Original article

\title{
Evaluating occupational morbidity among energy enterprise employees in industrial region of Kazakhstan
}

\author{
Olga V. Grebeneva ${ }^{1}$, Dina H. Rybalkina ${ }^{1}$, Lyazat K. Ibrayeva ${ }^{1}$, Almagul Zh. Shadetova ${ }^{1}$, Elena A. Drobchenko ${ }^{1}$, \\ Natalya Yu. Aleshina ${ }^{1,2}$ \\ ${ }^{1}$ Karaganda State Medical University, Karaganda, Kazakhstan \\ ${ }^{2}$ Novosibirsk State Agrarian University, Novosibirsk, Russia
}

Received 29 September 2019, Revised 2 August 2020, Accepted 28 January 2021

C 2019, Russian Open Medical Journal

Abstract: Our research project was aimed at studying the effects of an electromagnetic field of industrial frequency (EMF-IF) on employees of an energy company in Kazakhstan.

Material and Methods - The object of our study was the health status of electricians (morbidity with temporary disability - MTD), engaged in the maintenance of power lines, relay protection systems and substations (220 and $500 \mathrm{kV}$ ) at an energy enterprise in Kazakhstan. The interrelation and dependence of the intensive MTD indicators on the hygienic factors at the workplace were determined, and the risks were calculated from the obtained data.

Results - Unfavorable workplace conditions caused an increase in disorders of the musculoskeletal system (up to $77 \%$ ), blood circulation (up to $65 \%$ ), nervous system (up to $52 \%$ ), skin diseases (up to $46.4 \%$ ), as well as the manifold rise of the likelihood of neoplasm growth and respiratory diseases. For electricians, the relationships between the nervous system disorders $(r=0.792)$, the circulatory system diseases $(r=0.573)$, the musculoskeletal system ailments ( $r=0.672)$ and the EMF-IF parameters were discovered. At the same time, the dependence of the incidence rates of various diseases in workers on EMF, as well as moderate to high computed relative risks, implied the occupational genesis of worklace ailments: for nervous system $-R^{2}=0.628$, cardiovascular system $-R^{2}=0.709$, skin $-R^{2}=0.729$, and musculoskeletal system $-R^{2}=0.413$.

Conclusion - As preventive measures for electricians, we recommended to wear individual exposure meters, to limit work in contact with EMF, to include an oncologist in the medical commission, and for trainees, to screen for oxidative stress proteins and chaperone proteins to exclude a predisposition to oncogenesis.

Keywords: electrician, morbidity with temporary disability, length of service, occupational morbidity.

Cite as Grebeneva OV, Rybalkina DH, Ibrayeva LK, Shadetova AZh, Drobchenko EA, Aleshina NYu. Evaluating occupational morbidity among energy enterprise employees in industrial region of Kazakhstan. Russian Open Medical Journal 2021; 10: e0319.

Correspondence to Dina H. Rybalkina. Address: Karaganda State Medical University, 40 Gogol St., Karaganda, Kazakhstan. Phone: +7 (747) 387 8299. E-mail: ystas666@list.ru.

\section{Introduction}

Work at energy enterprises is associated with a complex of hazardous and harmful production factors, among which physical factors, such as electromagnetic fields, noise, and microclimate, do not habitually meet hygienic standards. The occupational risks of the energy industry, due to the specifics of production, constitute the cause for the incidence of sickness among employees, but occupational pathology is not recorded. It is obvious that most occupational ailments are masked in the structure of general morbidity [1].

Malignant neoplasms are considered abroad occupational diseases, originating from exposure to low-frequency electromagnetic fields. For workers with occupational exposure to extremely low frequency magnetic fields (ELF-MF), the risk of developing acute myeloid leukemia and follicular lymphoma has been proven [2]. In South Korea, various cancers arising from exposure to ELF-MF are considered occupational. As of July 2017,
18 workers in the semiconductor industry were compensated for occupational diseases, including leukemia, aplastic anemia, brain cancer, breast cancer, lung cancer, malignant lymphoma, and ovarian cancer [3]. However, in Kazakhstan, occupational disorders generated by an exposure to electromagnetic fields of industrial frequency (EMF-IF), including malignant neoplasms, have not been yet established.

The goal of our research project was to reveal the occupational cause of ailments in the energy enterprise workforce exposed to EMF-IF in Kazakhstan.

\section{Material and Methods}

The objects of the study were the workplace conditions and health status of electricians at nine electrical substations (SS) of an energy enterprise in the Republic of Kazakhstan. The interrelations and dependence of the intensive indicators of the morbidity with temporary disability (MTD) on the hygienic factors at the 
workplace were determined, and the risks were calculated from the obtained data.

The design of our study included selection and formation of groups during 2017-2018 while implementing preliminarily planned research project, 'Developing scientific foundations to form a preventive environment necessary for maintaining public health.' Information about workplace conditions resulted from measuring the parameters of the workplace environment, whereas the data on the workers' health originated from the recorded cases of occupational illnesses over a five-year period.

We used the observation method based on retrospective cohort studies. Data collection was carried out in several stages. First, we grouped morbidity according to officially designated parameters, such as age, length of service, occupational groups, and a class of an ailment, according to the $10^{\text {th }}$ revision of the International Statistical Classification of Diseases and Related Health Problems (ICD-10 class). Then we analyzed the MTD incidence in three selected groups of electricians for each of nine analyzed SS over a five-year period according to officially designated parameters. The dynamics in the groups (length of service, age, and occupational) versus incidence levels and the MTD structure were assessed. We also investigated the dependence of MTD in electricians on the factors of the workplace environment, for which purpose the average levels of occupational factors and intensive indicators (total number of sick individuals, incidence of each disease, number of sick days per 100 workers, and duration of a single occasion of an ailment) were compared by ICD-10 classes in each group of electricians separately on each of nine SS.
The MTD of workers was studied by means of conventional methods, based on analyzing the sick leaves of employees, who worked in the profession for the period 2010-2014 for at least three months and who gave a written consent for the use of their personal data for the analysis. The analysis excluded the individuals who had worked at the enterprise for shorter periods of time, as well as workers who refused to share the data on their MTD cases.

A comprehensive assessment of the electricians' workplace features and conditions, as well as their labor process severity and intensity, was implemented, taking into account the service area and timing based on the results of (1) instrumental studies of the industrial microclimate (with mcroclimate measuring station Meteoscope-M), illumination (with TKA-PKM light meter), noise (by Assistant-Total sound level meter), electromagnetic radiation (via VE-METP-AT-50), along with gas and dust content in the air (by gas analyzer GANK-4) in the summer and winter seasons; and (2) the data from 2009 and 2014 reports on certification of workplaces.

All electricians were distributed among three groups in terms of their occupational activities: Group 1 (60 people), comprising of electricians engaged in the maintenance of power transmission lines (PTL); Group 2 (56 people), responsible for the relay protection and automation system (RPA); and Group 3 (45 workers), employed at substations (SS). The control group consisted of auxiliary workers and drivers, who were not associated with exposure to electromagnetic fields (114 people). The average age and length of service were, correspondingly, $41.6 \pm 0.5 \mathrm{yr}$. and $9.6 \pm 0.2 \mathrm{yr}$. for individuals in Group $1 ; 42.5 \pm 0.5 \mathrm{yr}$. and $11.6 \pm 0.2 \mathrm{yr}$. in Group 2; $43.6 \pm 0.8 \mathrm{yr}$. and $14.6 \pm 0.8 \mathrm{yr}$. in Group $3 ; 45.9 \pm 0.5 \mathrm{yr}$. and $11.0 \pm 0.5 \mathrm{yr}$. in the control group.

Table 1. Intensive MTD indicators (incidence of each disease) at an energy company in Kazakhstan

\begin{tabular}{|c|c|c|c|c|c|}
\hline ICD-10 classes & Incidence rate per 100 employees & Group 1 & Group 2 & Group 3 & Control \\
\hline \multirow{2}{*}{ TOTAL (regardless of ICD-10 class) } & individuals & $64.5 \pm 0.6$ & $82.9 \pm 0.7^{*}$ & $45.3 \pm 0.5$ & $75.9 \pm 0.4$ \\
\hline & cases & $50.3 \pm 0.5$ & $44.4 \pm 0.5$ & $57.4 \pm 0.5^{*}$ & $51.8 \pm 0.4$ \\
\hline \multirow{2}{*}{ Certain infectious and parasitic diseases } & individuals & $2.0 \pm 0.1$ & $2.1 \pm 0.1$ & 0 & $6.8 \pm 0.1$ \\
\hline & cases & $2.0 \pm 0.1^{*}$ & $1.1 \pm 0.1$ & 0 & $1.1 \pm 0.1$ \\
\hline \multirow{2}{*}{ Neoplasms } & individuals & 0 & 0 & $2.4 \pm 0.1$ & $4.8 \pm 0.1$ \\
\hline & cases & 0. & 0 & $9.9 \pm 0.2^{*}$ & $1.2 \pm 0.1$ \\
\hline \multirow{2}{*}{$\begin{array}{l}\text { Endocrine, nutritional, and metabolic } \\
\text { diseases }\end{array}$} & individuals & 0 & $1.1 \pm 0.1$ & 0 & $2.0 \pm 0.1$ \\
\hline & cases & 0 & $1.1 \pm 0.1 *$ & 0 & $0.4 \pm 0.1$ \\
\hline \multirow{2}{*}{ Diseases of the nervous system } & individuals & $0.5 \pm 0.1$ & $2.7 \pm 0.1^{*}$ & $2.5 \pm 0.1 *$ & $0.8 \pm 0.1$ \\
\hline & cases & $0.5 \pm 0.1$ & $1.6 \pm 0.1 *$ & $2.5 \pm 0.1^{*}$ & $0.8 \pm 0.1$ \\
\hline \multirow{2}{*}{ Diseases of the eye and adnexa } & individuals & $1.5 \pm 0.1$ & $1.6 \pm 0.1$ & $0.5 \pm 0.1$ & $1.3 \pm 0.1$ \\
\hline & cases & $1.5 \pm 0.1$ & $1.1 \pm 0.1$ & $0.5 \pm 0.1$ & $1.3 \pm 0.1$ \\
\hline \multirow{2}{*}{ Diseases of the ear and mastoid process } & individuals & $2.0 \pm 0.1^{*}$ & 0 & $1.5 \pm 0.1 *$ & $0.5 \pm 0.1$ \\
\hline & cases & $2.0 \pm 0.1^{*}$ & 0 & $1.5 \pm 0.1 *$ & $0.5 \pm 0.1$ \\
\hline \multirow{2}{*}{ Diseases of the circulatory system } & individuals & $7.1 \pm 0.2$ & $11.2 \pm 0.2^{*}$ & $5.0 \pm 0.2$ & $8.4 \pm 0.1$ \\
\hline & cases & $5.6 \pm 0.2 *$ & $5.3 \pm 0.2 *$ & $5.0 \pm 0.2$ & $4.4 \pm 0.1$ \\
\hline \multirow{2}{*}{ Diseases of the respiratory system } & individuals & $19.8 \pm 0.3$ & $24.1 \pm 0.4$ & $14.7 \pm 0.3$ & $23.5 \pm 0.2$ \\
\hline & cases & $15.2 \pm 0.3$ & $12.8 \pm 0.3$ & $17.3 \pm 0.3$ & $18.3 \pm 0.2$ \\
\hline \multirow{2}{*}{ Diseases of the digestive system } & individuals & $6.1 \pm 0.2$ & $7.0 \pm 0.2$ & $5.4 \pm 0.2$ & $8.6 \pm 0.1$ \\
\hline & cases & $3.0 \pm 0.1$ & $2.7 \pm 0.1$ & $5.9 \pm 0.2$ & $6.6 \pm 0.1$ \\
\hline \multirow{2}{*}{$\begin{array}{l}\text { Diseases of the skin and subcutaneous } \\
\text { tissue }\end{array}$} & individuals & $3.6 \pm 0.1^{*}$ & $8.6 \pm 0.2^{*}$ & $0.5 \pm 0.1$ & $1.5 \pm 0.1$ \\
\hline & cases & $1.5 \pm 0.1$ & $4.3 \pm 0.2^{*}$ & $0.5 \pm 0.1$ & $1.5 \pm 0.1$ \\
\hline \multirow{2}{*}{$\begin{array}{l}\text { Diseases of the musculoskeletal system and } \\
\text { connective tissue }\end{array}$} & individuals & $12.2 \pm 0.2^{*}$ & $15.0 \pm 0.3^{*}$ & $6.9 \pm 0.2$ & $9.6 \pm 0.2$ \\
\hline & cases & $11.2 \pm 0.2 *$ & $8.6 \pm 0.2$ & $8.4 \pm 0.2$ & $8.4 \pm 0.1$ \\
\hline \multirow{2}{*}{ Diseases of the genitourinary system } & individuals & $3.6 \pm 0.1$ & $2.7 \pm 0.1$ & $3.0 \pm 0.1$ & $3.5 \pm 0.1$ \\
\hline & cases & $3.0 \pm 0.1$ & $1.6 \pm 0.1$ & $3.0 \pm 0.1$ & $3.0 \pm 0.1$ \\
\hline Injury, poisoning and certain other & individuals & $6.1 \pm 0.2^{*}$ & $7.0 \pm 0.2^{*}$ & $2.5 \pm 0.1$ & $4.3 \pm 0.1$ \\
\hline consequences of external causes & cases & $4.6 \pm 0.2$ & $4.3 \pm 0.2$ & $2.5 \pm 0.1$ & $4.0 \pm 0.1$ \\
\hline
\end{tabular}

* $p<0.001$ for the incidence rate higher than in control group; cases - the number of illness cases per 100 workers; individuals - the number of sick people per 100 employees. 
Table 2. MTD per 100 employees across length of service groups of electricians by occupational morbidity categories at the energy enterprise in Kazakhstan

\begin{tabular}{|c|c|c|c|c|c|c|c|c|c|}
\hline \multirow{2}{*}{ ICD-10 classes } & \multirow{2}{*}{$\begin{array}{c}\text { Indicators of occupational } \\
\text { morbidity }\end{array}$} & \multicolumn{8}{|c|}{ Length of service, years } \\
\hline & & $0-4$ & $5-9$ & $10-14$ & $15-19$ & $20-24$ & $25-29$ & $30-34$ & Total \\
\hline \multirow{3}{*}{$\begin{array}{l}\text { Diseases of the nervous } \\
\text { system }\end{array}$} & cases & $2.0 \pm 0.1$ & $1.7 \pm 0.1$ & 0 & 0 & 0 & 0 & $7.7 \pm 0.4$ & $1.6 \pm 0.1$ \\
\hline & sick days & $31.3 \pm 4.1$ & $9.2 \pm 4.5$ & 0 & 0 & 0 & 0 & $120.5 \pm 8.0$ & $20.7 \pm 2.2$ \\
\hline & case duration & 15.3 & 5.5 & 0 & 0 & 0 & 0 & 15.7 & 13.0 \\
\hline \multirow{3}{*}{$\begin{array}{l}\text { Diseases of the } \\
\text { circulatory system }\end{array}$} & cases & $2 \pm 0.1$ & $2.5 \pm 0.1$ & $3.6 \pm 0.3$ & $12.5 \pm 0.4$ & $19.3 \pm 0.6$ & $18.2 \pm 1.3$ & $5.1 \pm 0.4$ & $6.2 \pm 0.1$ \\
\hline & sick days & $27.9 \pm 4.1$ & $30.8 \pm 4.5$ & $36.4 \pm 6.7$ & $248.4 \pm 6.3$ & $417.5 \pm 6.2$ & $81.8 \pm 15.0$ & $110.3 \pm 8.0$ & $109 \pm 2.2$ \\
\hline & case duration & 13.7 & 12.3 & 10.0 & 19.9 & 21.6 & 4.5 & 21.5 & 17.6 \\
\hline \multirow{3}{*}{$\begin{array}{l}\text { Diseases of the skin } \\
\text { and subcutaneous } \\
\text { tissue }\end{array}$} & cases & $4,1 \pm 0.2$ & $9.2 \pm 0.3$ & $5.5 \pm 0.3$ & $3.1 \pm 0.2$ & $3.5 \pm 0.2$ & 0 & 0 & $4.8 \pm 0.1$ \\
\hline & sick days & $29.9 \pm 4.1$ & $86.7 \pm 4.5$ & $20.0 \pm 6.7$ & $37.5 \pm 6.3$ & $21.1 \pm 6.2$ & 0 & 0 & $38.8 \pm 2.2$ \\
\hline & case duration & $\ldots .3$ & 9.5 & 3.7 & 12.0 & 6.0 & 0 & 0 & 8.1 \\
\hline Diseases of the & cases & $8.2 \pm 0.2$ & $12.5 \pm 0.3$ & $18.2 \pm 0.6$ & $9.4 \pm 0.4$ & $5.3 \pm 0.3$ & $9.1 \pm 0.9$ & $5.1 \pm 0.4$ & $9.8 \pm 0.1$ \\
\hline \multirow{2}{*}{$\begin{array}{l}\text { musculoskeletal system } \\
\text { and connective tissue }\end{array}$} & sick days & $64.6 \pm 4.1$ & $108.3 \pm 4.5$ & $209.1 \pm 6.7$ & $109.4 \pm 6.3$ & $71.9 \pm 6.2$ & $254.5 \pm 15$ & $48.7 \pm 8.0$ & $99.2 \pm 2.2$ \\
\hline & case duration & 7.9 & 8.7 & 11.5 & 11.7 & 13.7 & 28.0 & 9.5 & 10.2 \\
\hline
\end{tabular}

Cases - the number of illness cases per 100 workers; days - number of sick days per 100 employees, case duration - average duration of sickness in days.
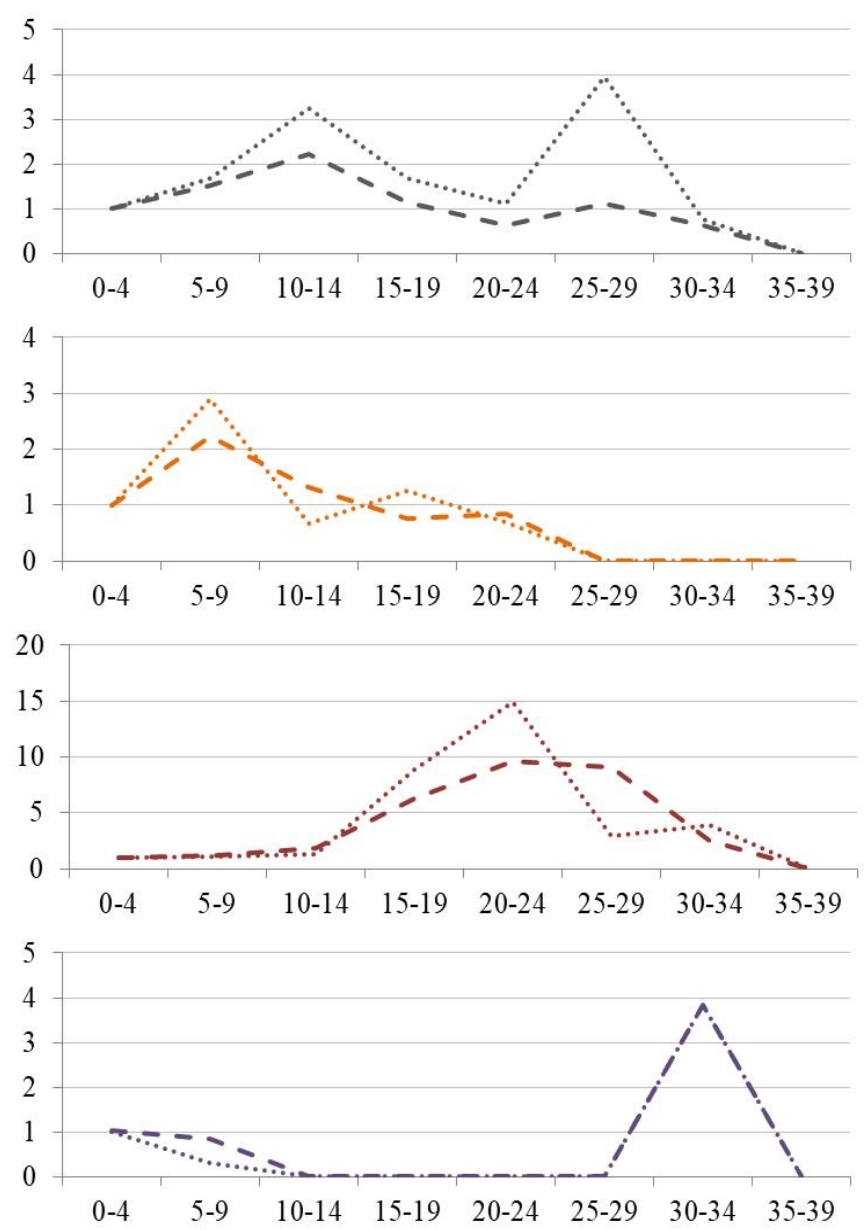

Figure 1. Relative risk of disease growth for musculoskeletal system (a), skin (b), circulatory system (c), and nervous system (d) among electricians at the energy enterprise in Kazakhstan.

Note: $x$-axis - length of employment groups (duration in years); $y$ axis - relative risk; dashed line - morbidity per 100 employees; dotted line - sick days per 100 employees.
Statistical data processing was conducted by using STASTICA 10 software via testing the hypothesis of the normal distribution, along with calculating the sample means $(\mathrm{M} \pm \mathrm{m})$ and their $95 \%$ confidence intervals, and the medians (Me) and their $25-75 \%$ quartiles. To compare the numerical values of the studied parameters, corresponding to the normal distribution and having equal standard deviations, the Student's $t$-test was used for unrelated groups. To compare the qualitative variables, we employed the Mann-Whitney and Kolmogorov-Smirnov tests for unrelated variables. For all those tests, we used the significance level of $p<0.05$, considering the Bonferroni correction. With a given statistical significance estimate $(p<0.05)$ in mind, we identified the closeness of the relationship (Pearson productmoment correlation) and the dependence of intensive MTD indicators on hygienic factors.

\section{Results}

Comparing the MTD levels of electricians in three assigned groups, who were in contact with equipment generating EMF-IF, with equivalent indicators in the control group of employees, we calculated the relative risks, the magnitude of which and the degree of causal relationships among health disorders and professions allowed us to consider various ailments attributable to occupation [4]. The greatest relative risk of developing nervous systme disorders, related to the number of cases and to the number of sick people, was found in RPA electricians (3.52 and 2.11 times) and SS electricians (3.26 and 3.26 times) (Table 1). There were no differences between the Groups 1 and 2, while differences were found between the indices of Group 1 vs. Group 3 (except for endocrine diseases), and Group 2 vs. Group 3 (for most ICD classes) $(p<0.001)$.

The next (by magnitude) risk was associated with skin diseases in RPA electricians (5.63 and 2.82 times) and PTL electricians (2.34 times). The risks of developing musculoskeletal diseases were identified in PTL electricians (1.27 and 1.33 times) and RPA electricians (1.56 times). Low risks of cardiovascular disease occurrence were identified solely among RPA electricians (1.33 and 1.20 times).

According to the data of epidemiological studies, the assessment of the causal relationship among health disorders and workplace conditions by the value of the relative risk with the corresponding etiological segment of $33 \%$ matches to the risk of 
occurrence of musculoskeletal disorders in PTL electricians. The relative risk from 1.5 to 2 and the etiological proportion of $33-50 \%$ reflect the average degree of occupational nature of the musculoskeletal disorders' risk in RPA electricians. If we agree with an opinion by Klebanov R.D. et al. that the possibility of developing work-related diseases arises at risks in the intervals from 2 to 3.2 with an etiological proportion of $51-66 \%$, then the risk of the nervous system diseases (2.47), and of skin and subcutaneous tissue diseases (2.70) for all electricians corresponds to a high degree of occupational causation, at which persistent health disorders may occur.

The revealed regularities of the prevalence of diseases among electricians coincide with the structure of the prevalence of diseases for the entire population of Karaganda Oblast, which is the most industrialized region of Kazakhstan. The levels of musculoskeletal system diseases in all three groups of electricians (PTL, RPA, SS), as well as their combined group, significantly exceeded (7.07, 8.69, 4.02 and 6.56 times) the prevalence of diseases of this type in comparison with the entire population of Karaganda Oblast (1722.78\%ooo). Same pattern is true for the class of diseases of the circulatory system $(3.70,5.85,2.58$ and $4.01)$, compared with the prevalence of diseases of this class among the entire population of Karaganda Oblast (1919.92\%ooo). High prevalence of diseases of the nervous system among electricians (2.04, 1.89, and 1.45 times) over similar morbidity levels in the population of the Karaganda Oblast (1313.22\%ooo) was noted in the RPA, SS, and combined groups of electricians. As for the class of skin diseases (2714.4\%ooo), a similar comparison revealed its high MTD for PTL and RPA electricians, as well as for all electricians combined (1.31, 3.15 and 1.51 times, respectively).

It should be noted that skin diseases in workers were detected only at $500 \mathrm{kV} \mathrm{SS}$, where the duration of a single sickness (14.0 days) was 1.44 times greater than the standard indicators for the electric power industry of the Unified Energy System (UES) (9.7 days). But an even higher numbers of cases and sick days per 100 employees were discovered for PTL electricians (9.35 times and 7.28 times) and RPA electricians ( 9.5 times and 8.47 times). The probable cause of this finding was a significant excess of the electric component of the EMF-IF equipment on open switchgears of the $500 \mathrm{kV}$ SS and PTL of the maximum permissible level (5 $\mathrm{kV} / \mathrm{m})$.

Nervous system-related MTD was often recorded at $220 \mathrm{kV}$ SS electricians. At all substations, we detected 6.0, 7.6 and 3.6 times higher than norm number of cases ( 0.7 per 100 employees), respectively. Same was true for number of sick days (an average of 8.7 per 100 employees): 5.4, 6.4 and 5.5 times higher than norm, correspondingly. A particularly pronounced excess of these indicators was noted among RPA electricians (7.7 times and 9.6 times), as well as at individual $220 \mathrm{kV}$ SS (20.43 times and 21.35 times).

The MTD for the classes of the circulatory system diseases and musculoskeletal system disorders was detected at all studied objects of the energy enterprise in Kazakhstan, with numerical values of several MTD indicators exceeding the permissible levels accepted within the UES. For circulatory system diseases, MTD indicators exceeded the norm by 1.6 to 7.9 times, and 1.6 times for $220 \mathrm{kV}$ SS, while for diseases of the musculoskeletal system, MTD exceeded the norm by 1.2-1.87 times at various $220 \mathrm{kV} \mathrm{SS}$, which confirmed the high risks of developing diseases of these ICD classes and also clarified workplace areas, requiring priority optimization of working conditions.

The difference between the actual morbidity rate, expressed in cumulative sick days per 100 workers, and the morbidity rate under optimal work environment, considering the average age and length of service, indicates the level of occupational health loss [4]. A low risk class (1), implying loss of occupational health at a level of $0.01-5.0 \%$, was identified for people in the conditional control group (administrative staff). The permissible risk class (2) means 5.01-16.0\% level of occupation-related health loss, significant risk class (3) stands for $16.01-35.0 \%$ of health loss, and high-risk class (4) indicates $35.01-60.0 \%$ loss of occupational health. According to the average values of intensive indicators in the length of service groups of electricians vs. standard indicators for the UES industry, the level of profession-related health loss among electricians was $58 \%$ for the class of diseases of the nervous system, $39 \%$ for diseases of the circulatory system, $50 \%$ for skin diseases, and $11.7 \%$ for the musculoskeletal system (Table 2 ).

Professional-related risk of developing diseases for four assigned groups of electricians (PTL, RPA, SS, and control) was confirmed by their dynamics over the length of service. In electricians, the occupational conditionality of the diseases' growth risk began increasing in the classes of musculoskeletal system diseases and skin diseases after 10 years of employment, in the classof circulatory system diseases after 14 years of work, and in the class of nervous system disorders after 30 years of service.

A similar dynamic of the relative risk growth for diseases (by the number of cases and cumulative sick days per 100 employees) is presented in Figure 1, where the growth of risks for skin diseases was noted after five years of work, whereas for diseases of the circulatory system, only after 20 years.

A correlation between the intensity of the magnetic (electrical) component of the EMF-IF at the workplace of electricians with their MTD indicators was confirmed for three ICD-10 classes: for diseases of the nervous system with EMF intensity (by number of sick days: $r=0.79, p=0.006$, and by number of sick individuals and cases of sickness per 100 employees: $r=0.77, p=0.009$ ); for diseases of the circulatory system with EMF intensity (by number of sick people: $r=0.57, p=0.03$ ); for diseases of the musculoskeletal system (by number of sick individuals and cases of sickness) with EMF intensity: $r=0.63, p=0.008$ and $r=0.67, p=0.004$, correspondingly; and for diseases of the musculoskeletal system (by number of sick individuals and cases of sickness) with electric field strength: $r=0.62, p=0.01$ and $r=0.53, p=0.03$, respectvely.

The risk of meningioma in workers, contacting with EMF, can now be calculated, taking into account their initial age and length of service [5]. It has been established that, for the majority of electricians with work experience at the energy enterprise of Karaganda Oblast up to 20 years, the risk of developing meningiomas was characterized as permissible. The risk index for PLT electricians, under magnetic field exposure of $3.5 \mu \mathrm{T}$, may exceed the level of acceptable risk for the length of service of over 20 years, and especially after 30 years of employment, when it is classified as moderate (0.052106 and 0.078138). This requires supplementary measures to reduce the risk by limiting work in contact with EMFs to 19 years and 22 years, respectively.

The effects of EMF-IF on the incidence of diseases of the genitourinary system were detected in electricians with experimental confirmation of changes in kidney function, which led to an increase in creatinine and urea concentrations in blood 
plasma $(p<0.001)$, accompanied by severe vascular stasis in the renal cortex and a decrease in the number of erythrocytes in the glomerular capillaries [6]. The experiment also showed that longterm exposure to EMF could lead to oxidative damage to the liver and spleen with an increase in alanine aminotransferase (ALT) and aspartate aminotransferase (AST), and a decrease in glutathione peroxidase and superoxide dismutase, along with serum immunoglobulins [7]. Alternatively, we did not discover any statistically significant differences in the MTD for the ICD-10 classes of diseases of the digestive system and diseases of the genitourinary system between the electricians and the control group.

\section{Discussion}

Established by our results occupational conditionality of diseases of the nervous system, circulatory system, musculoskeletal system, and skin from the parameters of the EMFIF in electricians at the energy enterprise in Kazakhstan, exposed to EMF-IF, could be explained by the peculiarities of the pathogenetic mechanism, cuaisng changes that provoke oncogenesis. Recent experimental studies established the pathophysiological mechanism of the damaging effect of lowfrequency EMF on the cell and cellular elements in the human body. The synthesis of stress proteins under the EMF influence was regarded as the principal mechanism of interaction between EMF and DNA in Biolnitiative Report (2012) [8]. This review emphasized that the DNA molecule is particularly vulnerable to EMF damage due to its double-helix configuration. Changes in the properties of stress proteins as a result of oxidative damage can lead to a decrease and loss of muscle strength. The specific response of individual cells, which is called cellular stress, develops to the effect of EMF earlier than to thermal stimuli: the threshold energy of the EMF stimulus is a billion times weaker than the thermal stimulus. With an increase in the EMF intensity, the number of DNA lesions may gradually increase as well, which indicates a dose-response relationship for low frequency EMF. Cellular stress proteins are synthesized when cells encounter stimuli, damaging macromolecules, and stress proteins help in the repair and transport of these molecules. Thermal stimuli, which triggered the synthesis of protective proteins, were considered extremely dangerous for the cell, but now we realize that nonthermal EMF stimuli induce the same defense reactions in cells. It is known that different types of cells react to EMF, both in vivo and in vitro, primarily epithelial, endothelial, and epidermal cells, as well as cardiac muscle cells and fibroblasts. The cellular stress response is widespread rather than universal. With repeated exposure to EMF stress, protein synthesis declines with each repetition. A decrease in the synthesis of stress proteins under constant exposure to EMF could predispose to oncogenesis. A few authors noted a decrease in the expression of heat shock proteins with age, which indicated a change in adaptation to the effects of EMF in older age groups, along with an increased risk of various pathogenetic processes [9].

More evidence is currently available regarding the EMF effects on the neuropsychiatric health of employees. When evaluating the subjective symptoms of self-assessment of PTL workers, $53.5 \%$ of them complained at headaches, $35.6 \%$ mentioned fatigue, $32.5 \%$ stated difficulty in concentrating, $30.4 \%$ sufferred from dizziness, $28.8 \%$ had attention disorders, $28.1 \%$ acquired nervousness, and $14.7 \%$ complained at tachycardia. When compared with the control group, the relationship among EMF exposure and neuropsychiatric symptoms was statistically significant $(p<0.05)$. With over 10 years of work experience, there was a risk of developing symptoms of depression, anxiety, and paranoid thinking [10]. We revealed that fatigue among workers at the energy enterprise was a significant factor in assessing occupational risk. Fatigue can be expressed as a linear function of time elapsed since the beginning of the workshift: $k=1+0.37 \times t$, where $k=y / 7.73$; $t$ is time, expressed as a fraction of the work shift [11].

Using the case-study of electric power industry enterprises of the industrial complex in Arkhangelsk, we developed mathematical models, reflecting the changes in the health of employees, detected in the course of their periodic medical examinations. Causal relationships of health disorders from exposure to harmful factors of the workplace environment and hazard class (classes 3.1-3.2) $\left(\chi^{2}=10.9, p<0.001\right)$ were established, with calculating the values of the relative risk (RR) and etiological fraction (EF). For operators, mechanics, repairmen, insulation workers, and electrical repair professionals, the risk for developing hearing diseases was: $\mathrm{RR}=2.3$ with the etiological share of $\mathrm{EF}=56.3$; and for diseases of the musculoskeletal system, it was slightly lower $\left(\chi^{2}=38.6, p<0.001, \mathrm{RR}=1.44, \mathrm{EF}=30.5\right)$ [12]. At the same time, the level of MTD, in terms of the number of all cases of sicknesses per 100 employees, as well as that of employees at an energy enterprise in Kazakhstan, was low (69.0 and below), which was not fully consistent with the established classes of working conditions and hazard classes. With a class of workplace conditions 3.1-3.2, the risk of occupational ailment is 0.0076 , while at the class 3.3 , it is 0.065 with a frequency of violatiing sanitary and epidemiological requirements for working conditions at electric power enterprises, on average, 0.36 per single inspection, or 1.56 at the $95^{\text {th }}$ percentile. In general, the potential harm to the health of workers at energy enterprises, associated with violations of sanitary legislation, was about 0.005 per single violation. At the same time, the levels of health risks for workers were increasing from the number of workers of 50 people at the facility with $2.15 \mathrm{E}-06$ to 3000 employees at the enterprise with 4.96E-05 [13]. At the enterprises of the electric power industry, only a few cases of occupational diseases were registered, with a high proportion of virtually healthy people (53.7\%).

The discovered negative correlation between the magnetic field intensity and the antioxidant activity of erythrocytes in Iranian electric welders was accompanied by a significant decrease in the activity of glutathione peroxidase and superoxide dismutase ( $p=0.001$ and $p=0.003$, respectively), compared with the control group [14]. Occupational exposure to EMF is also demonstrated by changes in the secretion of melatonin and cortisol, which affect the function of the circadian system [15]. Histaminemia, an increase in nitrotyrosine, S100B protein (calcium-binding protein synthesized in glial cells), antibodies to myelin antigens, Hsp27 and/or Hsp70 chaperone proteins (heat shock proteins) were detected in individuals with hypersensitivity, which should be interpreted as biomarkers from exposure to EMF [16]. Hence, the content of all aforementioned components should be determined, if there is a suspicion for an adaptation disorder to the chronic effects of EMF-IF in the working environment, in particular, in highly trained electricians with frequent cases of diseases, causing their temporary disability. 


\section{Conclusion}

1. Unfavorable conditions at the workplace of the energy enterprise in Kazakhstan caused a high growth segment of total MTD cases in all employees, particularly, up to $77 \%$ for diseases of the musculoskeletal system, up to $65 \%$ for blood circulation ailments, up to $52 \%$ for nervous system disorders, and up to 46.4 $\%$ for skin diseases.

2. In electricians, unfavorable workplace conditions increased the likelihood of emergence of skin diseases, causing temporary disability, by 39.7 times; of neoplasms, causing disability, by 10.9 times; of respiratory ailments, generating disability, by 13.2 times; and of musculoskeletal disorders, causing temporary disability, by 4.2 times.

3. In electricians, the occupational nature of their ailments due to their contact with EMF has been demonstrated by the close relationship between MTD indicators and diseases of the nervous system ( $r=0.792)$, circulatory system $(r=0.573)$, musculoskeletal system ( $r=0.672$ ) with EMF-IF; as well as the dependence of their morbidity rate for diseases of the nervous system $\left(R^{2}=0.628\right)$, cardiovascular system $\left(R^{2}=0.709\right)$, skin $\left(R^{2}=0.729\right)$ and musculoskeletal system $\left(R^{2}=0.413\right)$; along with computed high and medium relative risks.

4. As preventive measures for electricians, we recommended to wear individual exposure meters, to limit work in contact with EMF, to include an oncologist in the medical commission, and for trainees, to screen them for oxidative stress proteins and chaperone proteins to exclude their predisposition to oncogenesis.

\section{Conflict of Interests}

None declared. The study was carried out as a part of the Research Technical Project, 'Developing scientific foundations to form a preventive environment necessary for maintaining public health' as part of the scientific and technical progress "Development of the scientific foundations for the formation of a preventive environment in order to maintain public health".

\section{Ethical approval}

All procedures performed in studies, involving human participants, were in accordance with the ethical standards of the institutional and national research committee and with the 1964 Declaration of Helsinki and its later amendments, or comparable ethical standards. For this type of study formal consent is not required. This article does not contain any studies with animals performed by any of the authors.

\section{References}

1. Zabolotskaya NN, Muratova ZM. Risk factors in the power sector as the cause of morbidity of workers in the industry. Socio-economic and technical systems: research, design, optimization 2018; (2(78)): 83-90. https://elibrary.ru/item.asp?id=32830584.

2. Koeman T, van den Brandt PA, Slottje P, Schouten $L$, Goldbohm RA, Kromhout $\mathrm{H}$, et al. Occupational extremely low-frequency magnetic field exposure and selected cancer outcomes in a prospective Dutch cohort. Cancer Causes Control 2014; 25 (2): 203-214. https://doi.org/10.1007/s10552-013-0322-x.

3. Choi S, Cha W, Park J, Kim S, Kim W, Yoon C, et al. Extremely Low Frequency-Magnetic Field (ELF-MF) Exposure Characteristics among Semiconductor Workers. Int J Environ Res Public Health 2018; 15(4): 642. https://doi.org/10.3390/ijerph15040642.

4. Klebanov RD, Suvorova IV, Kosyachenko GE, Itpaeva-Lyudchik SL, Kucheneva EE, Zezyulya OG, et al. Evaluation criteria and indicators of production-related morbidity for a comprehensive analysis of the impact of working conditions on the health status of workers, professional risk assessment. Methodological recommendations. of the. Minsk, Belarus: State Institution "Republican Scientific and Practical Center of Hygiene". 2009; 32 p. http://med.by/methods/pdf/062-1109.pdf.

5. Health risk assessment under the influence of variable electromagnetic fields (up to $300 \mathrm{GHz}$ ) in populated areas. Guidelines MP 2.1.10.006112. Moscow, Russia: FederalCenter of Hygiene and Epidemiology of Rospotrebnadzor. 2012; $\quad 35 \quad p$. https://www.rospotrebnadzor.ru/documents/details.php?ELEMENT I $\mathrm{D}=4650$.

6. Gholampour F, Owji SM, Javadifar TS. Chronic Exposure to Extremely Low Frequency Electromagnetic Field Induces Mild Renal Damages in Rats. International Journal of Zoological Research 2011; 7(6): 393-400. https://dx.doi.org/10.3923/ijzr.2011.393.400.

7. Li BL, Li W, Bi JQ, Zhao JG, Qu ZW, Lin C, et al. Effect of long-term pulsed electromagnetic field exposure on hepatic and immunologic functions of rats. Wien Klin Wochenschr 2015; 127(23-24): 959-962. https://doi.org/10.1007/s00508-015-0732-8.

8. Sage C, Carpenter DO, Eds. Biolnitiative Report: A Rationale for a Biologically-based Public Exposure Standard for Electromagnetic Radiation. Section 1-28. Biolnitiative Working Group. 2012; 482 p. https://bioinitiative.org/table-of-contents.

9. Kuznik BI, Linkova NS, Havinson VKh. Heat shock proteins: changes related to aging, development of thrombotic complications, and peptide regulation of the genome. Advances in Gerontology 2011; 24(4): 539-552. https://elibrary.ru/item.asp?id=17306305.

10. Rizi HY, Dehghan H. Health problems from radiation of high-voltage facilities. Int J Env Health Eng 2013; 2: 1. https://doi.org/10.4103/ 2277-9183.106632

11. Korobov AV. Assessment of the professional risk of employees of energy technology as one of the main elements of the OSH management system. PhD Dissertation. Moscow. 2017; 126 p. https://mpei.ru/diss/Lists/FilesDissertations/270-Thesis.pdf.

12. Sokolova LA. Medico-ecological substantiation of the system of assessment of occupational risk to the health of workers of industrial enterprises of the city of Arkhangelsk. DSc Dissertation. Moscow, 2009; 246 p. https://www.dissercat.com/content/medikoekologicheskoe-obosnovanie-sistemy-otsenki-professionalnogo-riskazdorovyu-rabotnikov.

13. Andreeva EE. To the assessment of risks to the health of workers in the classification of objects of sanitary and epidemiological surveillance and the planning of inspections (for example, Moscow). Health risk analysis 2016; (2): 84-92. https://elibrary.ru/item. asp?id=26239550.

14. Sharifian A., Gharavi M., Pasalar P, Aminian O. Effect of extremely low frequency magnetic field on antioxidant activity in plasma and red blood cells in spot welders. Int Arch Occup Environ Health 2009; 82(2): 259-266. https://doi.org/10.1007/s00420-008-0332-2.

15. Lewczuk B, Redlarski G, Zak A, Ziółkowska N, Przybylska-Gornowicz B, Krawczuk M. Influence of Electric, Magnetic, and Electromagnetic Fields on the Circadian System: Current Stage of Knowledge. Biomed Res Int 2014; 2014: 169459. https://doi.org/10.1155/2014/169459.

16. Belpomme D, Campagnac Ch, Irigaray Ph. Reliable disease biomarkers characterizing and identifying electrohypersensitivity and multiple chemical sensitivity as two etiopathogenic aspects of a unique pathological disorder. Rev Environ Health 2015; 30(4): 251-271. https://doi.org/10.1515/reveh-2015-0027.

\section{Authors:}

Olga V. Grebeneva - MD, Chief Researcher, Institute of Public and Occupational Healthcare, Karaganda State Medical University, Karaganda, Kazakhstan, https://orcid.org/0000-0002-1758-3009.

Dina H. Rybalkina - PhD, Associate Professor, Department of Interna Medicine, Department of Internal Medicine No.3, Karaganda State Medical University, Karaganda, Kazakhstan, https://orcid.org/0000-0002-2041$\underline{1259}$. 
Lyazat K. Ibrayeva - MD, Head of the Department of Internal Medicine

No.3, Karaganda State Medical University, Karaganda, Kazakhstan,

https://orcid.org/0000-0002-9917-0258.

Almagul Zh. Shadetova - PhD, Leading Researcher, Institute of Public and Occupational Healthcare, Karaganda State Medical University, Karaganda, Kazakhstan, https://orcid.org/0000-0003-3029-855X.

Elena A. Drobchenko - graduate student, Department of Informatics and Biostatistics, Karaganda State Medical University, Karaganda, Kazakhstan, https://orcid.org/0000-0001-9291-7585.

Natalya Yu. Aleshina - Research Manager, Karaganda State Medical University, Karaganda, Kazakhstan; graduate student, Novosibirsk State Agrarian University, Novosibirsk, Russia. https://orcid.org/0000-00034883-5894. 